\title{
Keratoconus, keratoplasty thickness, and endothelial morphology
}

\author{
M. RUBEN, E. COLEBROOK, AND M. GUILLON \\ From Moorfields Eye Hospital, Department of Contact Lens and Prosthetics, \\ City Road, London ECIV 2PD
}

SUMMARY A group of successful keratonic grafts (51 eyes) up to 10 years from operation were examined to establish a relationship between graft thickness and acuity. Best acuity occurred in the grafts of normal corneal thickness. No grafts were thinner than normal; thus no tendency to keratonic thinning occurred. No relationship between age of graft and thickness was determined. Endothelial cell studies in vivo of a small number of grafts showed that cell counts a third of normal coexisted with normal acuity and corneal thickness.

It has been suggested that the keratoconus graft can after a time show keratonic features of the primary disease. The present work measured the corneal graft thickness in 51 eyes to establish whether after a time the graft besame abnormally thin. According to Ruben (1972) many grafts were thicker than normal cornea, and the greater the thickness the more abnormal the corrected acuity was likely to be. These findings were assumed to be related to endothelial dysfunction and/or stromal fibrosis and corneal irregularity.

In the present study the grafts were only of keratonic eyes and graft eye groups were compared as to their thickness and keratometry. Further, for a few patients with acuity corrected to normal the endothelial mosaic was studied by means of slit-lamp macrophotography and any correlation with corneal thickness was noted. A study of the same group of patients as to acuity, contact lens wear, and effects on curvatures and corneal sensitivity is reported separately (Rubens and Colebrook, 1979a, b).

It is accepted that at the time of operation the fresh donor cadaver material is almost always thicker than normal cornea, and that often during the operation procedure both thinning and clearing of the graft does occur. While this may not be indicative of endothelial function, but rather the drying of the graft, it will be expected that after several years the clear grafts would vary according to the degree of endothelial survival. If keratoconus is to recur in a graft, one would expect some thinning associated with steepening of the graft.

In all the grafts analysed the recipient aperture and

Correspondence to $\mathrm{Mr}$ M. Ruben. graft donor diameter were the same. The suturing was done by the continuous Perlon method to form a watertight junction, and the anterior chamber was re-established with Miochol solution (acetylcholine chloride and mannitol). This procedure, even with relaxation of the sutures and subsequent 'cheese cutting' of sutures, shows a tendency to produce a flatter than normal cornea. Analysis of the keratometry of keratoconus grafts showed that grafts steepened less than $0.2 \mathrm{~mm}$ of radius with an average time of 4 years from surgery (Ruben and Colebrook, 1979). This steepening may well be due to the graft taking up its normal plasticity and elasticity after removal of the sutures and thus not a keratoconus factor. The results of this report relate thickness to acuity. If a keratoconic progression is present, one would expect loss of acuity as well as the cornea to become thinner.

\section{Patients and methods}

The patients were recalled for pachometry, and the average age of the grafts was 57.6 months. The oldest graft was 10 years and the youngest 7 months from time of operation. The instrument used was the Haag-Streit pachometer attached to the slit-lamp 90 model.

Seven patients, totalling 9 grafts averaging $56 \cdot 1$ months after operation, were recalled for a second visit. At that visit corneal thickness was again measured but by means of an electronic pachometer based on the Haag-Streit model. The modified instrument enabled direct recording. Hence a minimum of 10 measurements were taken per eye, the mean and standard deviation being automatically calculated. 
Table 1 Corneal grafts thickness versus cells $/ \mathrm{mm}^{2}$

\begin{tabular}{|c|c|c|c|c|}
\hline \multicolumn{2}{|c|}{ Case } & \multirow{2}{*}{$\begin{array}{l}\text { Cells } / \mathrm{mm}^{2} \\
1250 \cdot 83 \pm 154 \cdot 04\end{array}$} & \multirow{2}{*}{$\begin{array}{l}\text { Thickness } \\
0.558 \pm 0.014\end{array}$} & \multirow{2}{*}{$\frac{V A}{6 / 6}$} \\
\hline 1 & $\mathbf{R}$ & & & \\
\hline & $\mathbf{L}$ & $878 \cdot 24 \pm 416 \cdot 88$ & $0.520 \pm 0.027$ & $6 / 9$ \\
\hline \multicolumn{2}{|l|}{2} & $841 \cdot 05 \pm 92.97$ & $0.578 \pm 0.017$ & $6 / 6^{-2}$ \\
\hline \multicolumn{2}{|l|}{3} & $1817 \cdot 75 \pm 263 \cdot 32$ & $0.511 \pm 0.023$ & $6 / 6^{-2}$ \\
\hline \multicolumn{2}{|l|}{4} & $1556 \cdot 98 \pm 204 \cdot 56$ & $0.565 \pm 0.016$ & $6 / 6$ \\
\hline \multicolumn{2}{|l|}{5} & $1011 \cdot 29 \pm 169 \cdot 60$ & $0.540 \pm 0.008$ & $6 / 6$ \\
\hline \multicolumn{2}{|c|}{ Mean } & $1226.02 \pm 393.84$ cells $/ \mathrm{mm}^{2}$ & $0.545 \pm 0.026$ & $6 / 6$ \\
\hline
\end{tabular}

Table 2 Normal thickness versus cell count

\begin{tabular}{cllll}
\hline Case & & Cells $/ \mathrm{mm}^{2}$ & Thickness & VA \\
\hline 6 & R & $3532 \cdot 42 \pm 228 \cdot 58$ & $0 \cdot 564 \pm 0.017$ & $6 / 5$ \\
7 & L & $3029 \cdot 20 \pm 176 \cdot 39$ & $0 \cdot 507 \pm 0.008$ & $6 / 5$ \\
8 & R & $3666 \cdot 85 \pm$ & $0 \cdot 571 \pm 0.026$ & $6 / 5$ \\
9 & R & $3096 \cdot 77 \pm 403 \cdot 51$ & $0 \cdot 521 \pm 0.014$ & $6 / 5$ \\
10 & R & $3288 \cdot 58 \pm 49 \cdot 73$ & $0.523 \pm 0.010 \mathrm{~mm}$ & $6 / 5$ \\
11 & & $2787 \cdot 87 \pm 369 \cdot 10$ & $0.527 \pm 0.018 \mathrm{~mm}$ & $6 / 5$ \\
Mean & $3233.62 \pm 328.38$ cells $/ \mathrm{mm}^{2}$ & $0.549 \pm 0.029$ & $6 / 6$ \\
\hline
\end{tabular}

Further, the endothelial mosaic was photographed by the noncontact technique described by Zantos and Holden (1978). With our particular arrangement the initial linear magnification obtained varied between 8.9 and 20 times. Cell counting was performed on the screen of a slide-projecting system with a linear magnification of 20 times. As a control, pachometry and endothelial photography were performed on the 6 eyes of normal young adults (Tables 1 and 2).

\section{Results}

Fifty-one graft eyes were examined. The lowest reading in the 'vision line' was $0.47 \mathrm{~mm}$ and the thickest $0.85 \mathrm{~mm}$. All eyes had measurable vision,

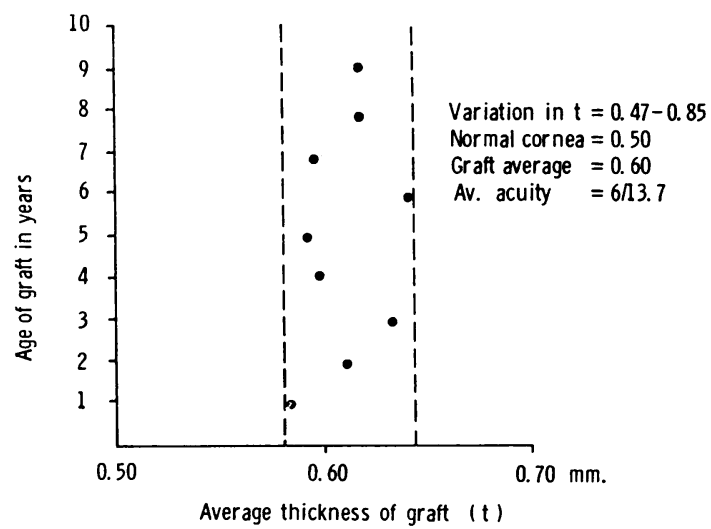

Fig. 1 Age of graft compared with thickness and the average acuity with spectacles was $6 / 13 \cdot 7$. The average corneal thickness was 0.60 (Fig. 1).

The results for different graft age groups are as follows (Table 3 ):

Table 3

\begin{tabular}{ll}
\hline Age of graft & Thickness \\
\hline Under 1 year & 0.58 \\
1 & 0.61 \\
2 & 0.63 \\
3 & 0.59 \\
4 & 0.58 \\
5 & 0.63 \\
6 & 0.59 \\
7 & 0.62 \\
$8-10$ & 0.62 \\
\hline
\end{tabular}

The tolerances for measurement of the corneal thickness by the Haag-Streit pachometer are \pm 0.02 , and therefore the correlation of thickness for each age group of graft shows no significant trend (Fig. 1).

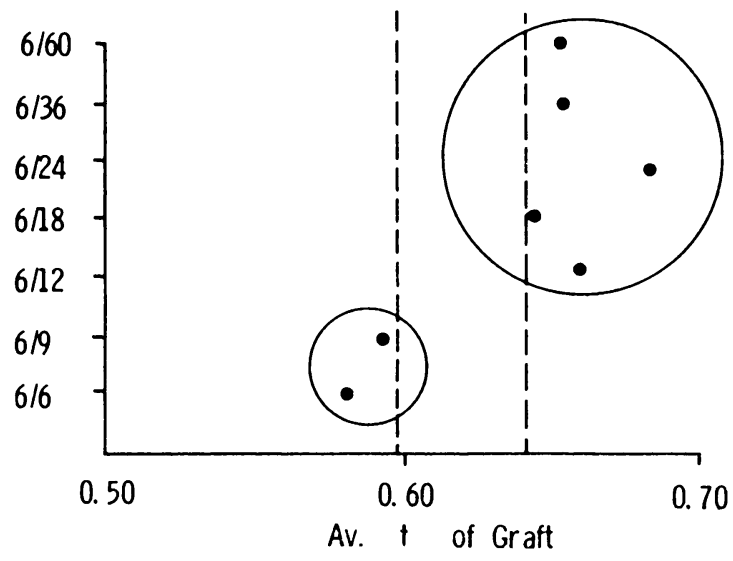

Fig. 2 Acuity (corrected) of grafted eye compared with average thickness

But the comparison of acuity with thickness (Fig. 2) shows the following results (Table 4):

Table 4

\begin{tabular}{ll}
\hline Acuity & Average thickness \\
\hline $6 / 6$ or better & 0.57 \\
$6 / 9$ & 0.59 \\
$6 / 12$ & 0.65 \\
$6 / 18$ & 0.63 \\
$6 / 24$ & 0.68 \\
$6 / 36$ & 0.64 \\
$6 / 60$ & 0.64 \\
\hline
\end{tabular}


There appears to be a sudden significant change in thickness related to acuity when the cornea becomes thicker than $0.62 \mathrm{~mm}$.

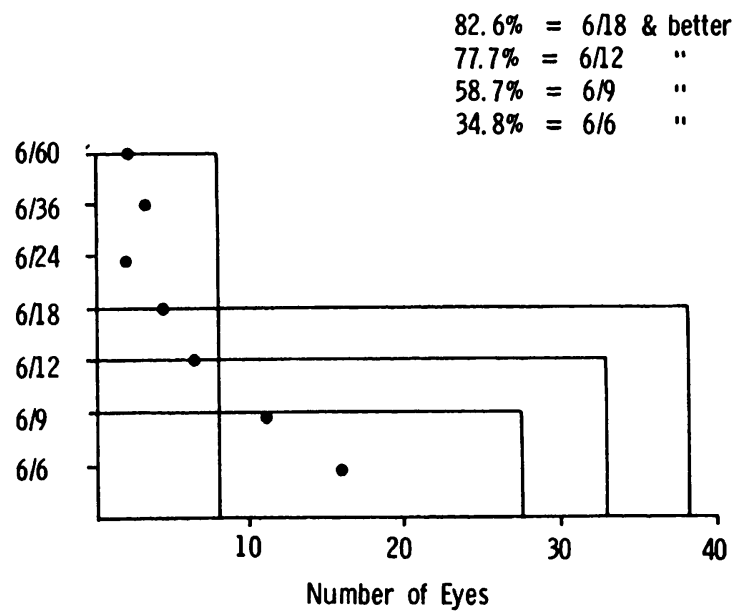

Fig. 3 Spectacle corrected acuity distribution

The distribution of acuity in 46 eyes where spectacle acuity was measured (Fig. 3 ) is as follows (Table 5):

Table 5

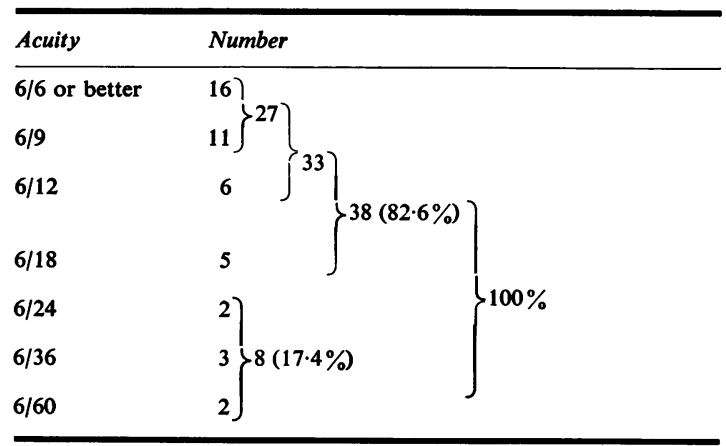

Therefore $82.6 \%$ had distance vision of $6 / 18$ or better with spectacles, and N5 for near with suitable addition where necessary.

The results obtained for selected corneal graft patients and normal subjects are recorded in Tables 1 and 2. All patients had normal corrected VA and there was no significant difference in corneal thickness between the mean of the 2 groups: $0.545 \mathrm{~mm}$ $(\mathrm{S} / \mathrm{D} \pm 0.026 \mathrm{~mm})$ for grafted eyes and $0.549 \mathrm{~mm}$ $(\mathrm{S} / \mathrm{D} \pm 0.029 \mathrm{~mm})$ for the control group. Endothelial cell photography on the contrary showed striking differences between the 2 groups. Cell density was lower for the corneal graft patients than for any patient of the control group: range of corneal graft densities 841 to 1817 cells $/ \mathrm{mm}^{2}$ and control group cell densities 2787 to 3666 cells $/ \mathrm{mm}^{2}$. The mean density of the control group was 2.67 times that of the corneal graft and this without any effect on corrected VA and corneal thickness.

In addition changes in cell morphology are encountered after corneal graft. Some patients showed large variations in cell sizes within the same photographic record in grafts (Fig. 4) but not in the control group (Fig. 5). In some instances there was total absence of single cells or group of cells (Fig. 6).

\section{Conclusion}

Even after 10 years in some instances and for an average of 4 years keratoconus grafts showed an increase in corneal thickness. If an upper limit of 0.54 for normal is allowed, only $15 \%$ of the grafts had thicknesses equal to or below this figure. The average thickness of 0.60 represents at least a $15 \%$ increase in thickness if normal cornea is taken to be $0.52 \pm 0.02$. Therefore there is no evidence of graft cornea becoming thin or keratonic. Furthermore,

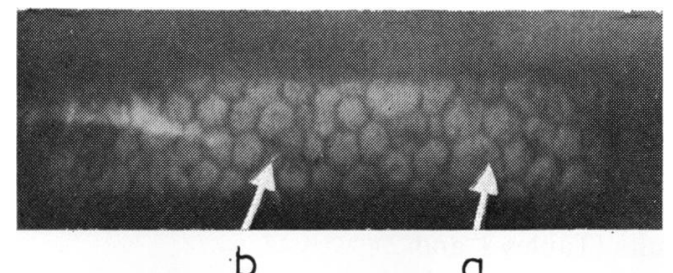

Fig. 4 Macrophotography of endothelial cell. Corneal graft patient showing enlarged cells (arrow a) and variation in size (arrow b)

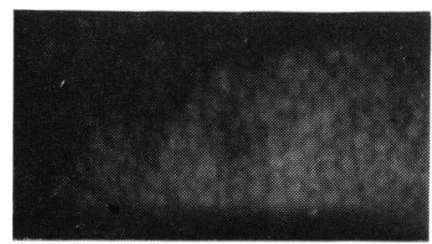

Fig. 5 Macrophotography of endothelial cell. Normal patient

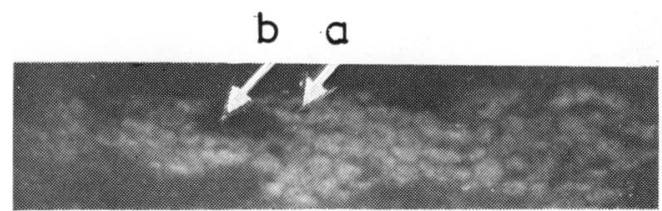

Fig. 6 Macrophotography of endothelial cell. Corneal graft patient showing absence of cells (arrows a and b) 
when thickness was compared with the age of the graft, there was no significant variance in the thickness.

But when the acuity was compared with the thickness a relationship was obvious. It appeared that substantial loss of acuity resulted when thickness was more than 0.62 . Such grafts, while clear and in some instances giving 6/6 acuity, nevertheless in many eyes are likely to be associated with subnormal acuity.

The results obtained for the endothelial study must be considered as a preliminary report, giving an indication of the changes occurring after corneal grafting and the effects they have on corneal physiology. The details of the measurement techniques will be published later. The main conclusions reached are that normal thickness is still maintained with endothelial counts a third of normal.

It remains to be proved whether those grafts associated with thicker than normal cornea had even a more diverse endothelial morphology than seen in this group. The reasons for endothelial cell death of the donor disc are several, and it is not yet determined whether cell loss is peripheral or distributed sporadically overall. Similar morphological changes occurring gradually as the graft ages have been reported by Mishima et al. (1979) but not with the absence of cells as seen in some of the grafts reported in this communication.

\section{References}

Mishima, S., Sakimoto, T., and Sawa, M. (1979). Transactions of the International Medical Symposium of Soft Lenses, Brugge (in press).

Ruben, M. (1972). In Casey, T. A., Corneal Grafting, p. 144. Butterworths: London.

Ruben, M., and Colebrook, E. (1979a). Keratoplasty sensitivity. British Journal of Ophthalmology, 63, 265-267.

Ruben, M., and Colebrook, E. (1979b). Keratoconus keratoplasty curvatures and contact lens wear. British Journal of Ophthalmology, 63, 268-273.

Zantos, S., and Holden, B. (1978). The corneal endothelium. International Contact Lens Clinic, 5, 10-14. 